\title{
Exigências Nutricionais de Zebuínos: Proteína
}

\section{Pedro Veiga Rodrigues Paulino², Marcos Antônio Lana Costa ${ }^{3}$, Sebastião de Campos Valadares Filho4, Mário Fonseca Paulino4, Rilene Ferreira Diniz Valadares ${ }^{5}$, Karla Alves Magalhães ${ }^{2}$, Marlos Oliveira Porto ${ }^{6}$, Kamila Andreatta}

\begin{abstract}
RESUMO - Com o objetivo de determinar as exigências protéicas de zebuínos, foi conduzido um experimento no Departamento de Zootecnia da Universidade Federal de Viçosa, utilizando-se 19 novilhos castrados, com peso vivo médio inicial de 270 kg, mantidos em confinamento. Quatro animais foram abatidos após o período de adaptação, compondo o grupo referência. Dos 15 animais restantes, três foram designados ao grupo mantença e os 12 demais distribuídos em três tratamentos com diferentes níveis de concentrado nas dietas (5, 35 e 65\%), na base da matéria seca (MS) total, em delineamento inteiramente casualizado, com quatro repetições. As dietas foram formuladas de forma a serem isoprotéicas. O volumoso foi constituído de pré-secado de capim-braquiária (Brachiaria brizantha) e de capim-tifton 85 (Cynodon sp.). O conteúdo de proteína retido no corpo foi estimado por meio de equação de regressão do logaritmo do conteúdo corporal de proteína, em função do logaritmo do peso de corpo vazio (PCVZ). Derivando-se a equação de predição do conteúdo corporal de proteína, foram obtidas as exigências líquidas de proteína para ganho de 1 kg de PCVZ. As exigências líquidas de proteína para ganho diminuíram com o aumento do peso vivo (PV) dos animais. A exigência líquida de proteína encontrada para um animal com PV de $400 \mathrm{~kg}$ foi de 106,84 g/kg de ganho de peso de corpo vazio (GPCVZ), enquanto para um animal de $200 \mathrm{~kg}$ foi de 129,01 g por kg de GPCVZ. As exigências de proteína metabolizável para mantença (PMm) e ganho de peso (PMg) estimadas foram de 339,88 e 217,14 g/kg PV, respectivamente, para um bovino castrado de $400 \mathrm{~kg}$ de PV. Para esse mesmo tipo de animal, as exigências de proteína degradável e não-degradável no rúmen foram de, respectivamente, 830,86 e 4,46 g/dia, correspondendo à exigência de proteína bruta de 835,32 g/dia.
\end{abstract}

Palavras-chave: exigências, proteína, zebuínos

\section{Nutritional Requirements of Zebu Cattle: Protein}

ABSTRACT - A trial involving nineteen zebu steers with initial live weight of $270 \mathrm{~kg}$ was conducted with the objective of determining their protein requirements. Four steers were slaughtered at the beginning of the trial, compounding the reference group, three were fed at maintenance level and the remaining were uniformly allotted to a complete randomized design, of three treatments, with different levels of concentrate in the diets (5, 35, $65 \%$, in the total dry matter basis). As roughage was used Brachiaria brizantha and Cynodon sp. haylage. The diets were isonitrogenous and the animals were fed ad libitum. The protein content retained in the body was estimated by a regression equation obtained between the logarithm of the body content of protein and the logarithm of the empty body weight (EBW). The net requirements of protein for $1 \mathrm{~kg}$ of empty body gain (EBG) were determined as the derivative of the equation of prediction of protein body content. The protein requirements for gain decreased as the live weight increased. The protein requirement found for an animal of $400 \mathrm{~kg}$ of live weight was $106.84 \mathrm{~g} / \mathrm{kg}$ EBW, while for an animal of $200 \mathrm{~kg}$, was $129.01 \mathrm{~g} / \mathrm{kg}$ EBW. Considering a steer of $400 \mathrm{~kg}$ of live weight, the estimated metabolizable requirements of protein for maintenance $\left(\mathrm{MP}_{\mathrm{m}}\right)$ and gain $\left(\mathrm{MP}_{\mathrm{g}}\right)$ were, respectively, 339.88 and $217.14 \mathrm{~g} / \mathrm{kg} \mathrm{LW}$. For this type of animal, the daily protein requirements in terms of degradable and undegradable protein were, respectively, 830.86 and $4.46 \mathrm{~g}$. The requirement of crude protein was $835.32 \mathrm{~g} / \mathrm{d}$.

Key Words: requirements, protein, zebu cattle

\footnotetext{
${ }^{1}$ Parte da dissertação de mestrado do primeiro autor apresentada a UFV.

2 Estudantes de Doutorado DZO/UFV, Viçosa, MG (pveiga@vicosa.ufv.br; kmagalhães@vicosa.ufv.br).

3 Zootecnista, M.Sc. REHAGRO (marcos@rehagro.com.br).

${ }^{4}$ Professores do DZO/UFV, Viçosa, MG (scvfilho@ufv.br; mpaulino@ufv.br).

${ }^{5}$ Professora do DVT/UFV, Viçosa, MG (rilene@ufv.br).

${ }^{6}$ Graduando em Medicina Veterinária UFV, Bolsista de Iniciação Científica PIBIC/CNPq.

${ }^{7}$ Graduanda em Zootecnia - UFV. Bolsista de Iniciação Científica (kamilandreatta@yahoo.com.br).
} 


\section{Introdução}

Apesar de o Brasil ser o país que abriga o maior rebanho bovino comercial do mundo, estimado em 167 milhões de cabeças (ANUALPEC, 2002), com grande predominância de animais com algum grau de sangue zebuíno, ainda predominam sistemas de produção pouco eficientes, tanto produtiva quanto economicamente. Os índices de produtividade observados em nossas condições, apesar de seguirem uma tendência lenta de melhora, insistem em classificar a pecuária de corte brasileira como uma atividade ineficiente e extrativista. Embora se possa encontrar "ilhas" de desenvolvimento, constata-se que a realidade da maioria das propriedades dedicadas à exploração da pecuária de corte se encontra em defasagem tecnológica.

Entretanto, as pressões do mercado, cada vez mais exigente e extremamente dinâmico e mutável, praticamente impõem um novo conceito em exploração pecuária. A adoção de tecnologias adequadas a cada tipo de sistema produtivo, com o intuito de se produzir mais, melhor e a baixo custo torna-se imprescindível para a sobrevivência do empresário rural. Obviamente, essa tecnologia deve ser desenvolvida em nível de Brasil, onde a composição do rebanho, os alimentos disponíveis e o clima são típicos de país tropical.

O manejo nutricional é, sem dúvida, um dos principais responsáveis pela baixa eficiência produtiva da pecuária brasileira. O estudo da composição dos alimentos e a determinação das exigências nutricionais de nossos animais, criados em nossas condições, parece ser um dos caminhos para se alcançar as melhorias almejadas.

Alguns autores têm procurado estabelecer as exigências nutricionais de bovinos de corte no Brasil, com os primeiros trabalhos sendo desenvolvidos na década de 80 (Salvador, 1980; Margon, 1981; Teixeira, 1984, Silva Sobrinho, 1984; Carvalho, 1989). Nos anos 90 vários trabalhos envolvendo a determinação das exigências nutricionais de bovinos de corte em território brasileiro foram publicados (Gonçalves et al., 1991a,b; Lana et al., 1992; Pires et al., 1993; Soares, 1994; Boin, 1995; Fontes, 1995; Freitas, 1995; Araújo et al., 1998; Estrada et al., 1997; Ferreira et al., 1999; Paulino et al., 1999; Rocha et al., 1999; Signoretti et al., 1999), e a partir de então outros trabalhos têm sido conduzidos (Véras et al., 2000; Backes et al., 2002; Bulle et al., 2002; Silva et al., 2002; Veloso et al., 2002; Carvalho et al., 2003; Paulino et al., 2003). Apesar do esforço, o volume de informações disponíveléainda muito limitado e insuficiente para definição de normas brasileiras de exigências nutricionais para gado de corte. Assim, as rações para ruminantes, em sua maioria, ainda são balanceadas a partir de tabelas elaboradas em países com ambiente, alimentos e animais diferentes dos encontrados nas condições brasileiras (Véras et al., 2000).

O estudo das exigências nutricionais de gado de corte no Brasil tem envolvido, principalmente, a determinação dos requerimentos de energia, proteína, macrominerais e, em menor intensidade, de aminoácidos, bem como a eficiência de utilização da energia para mantença e ganho de peso. Como os requisitos nutricionais diferem entre machos inteiros e castrados, devem ser estabelecidos separadamente (Fontes, 1995). Entretanto, quando se analisam as pesquisas desenvolvidas no país, constata-se que a maioria dos trabalhos envolvendo a determinação das exigências nutricionais de bovinos de corte foi realizada com machos inteiros.

Tão importante quanto a energia, a determinação das exigências de proteína, seja para mantença seja para crescimento, é imprescindível. A demanda de proteína para mantença de um bovino é igual às perdas metabólicas fecais e urinárias, além daquelas perdas de proteína por descamação. A quantificação dessas perdas é relativamente difícil, principalmente em relação às perdas metabólicas fecais, uma vez que é necessário separar as perdas microbianas nas fezes das verdadeiras perdas metabólicas fecais, o que exige um procedimento mais trabalhoso. O NRC (1996) adotou, a partir do trabalho de Wilkerson et al. (1993), um valor diário de exigência de proteína metabolizável para mantença de 3,8 g/kg PV $\mathrm{PV}^{0,75}$.

Já as exigências líquidas de proteína para crescimento e terminação são dependentes do conteúdo de matéria seca livre de gordura no peso ganho. Variam, portanto, em virtude da raça, classe sexual e taxa de ganho de peso. Em decorrência dessa variação no conteúdo do ganho, observa-se que os requerimentos líquidos de proteína para ganho são maiores em bovinos inteiros que em castrados e em animais de maturidade tardia que em animais mais precoces (Geay, 1984).

A partir do conhecimento da eficiência de utilização da proteína, pode-se converter as exigências líquidas em exigências de proteína metabolizável. O NRC (1996), considerando que essa eficiência varia com o peso vivo, assume eficiência constante de 49,2\% 
para animais com peso vivo superior a $300 \mathrm{~kg}$ e, para aqueles com peso inferior a $300 \mathrm{~kg}$, adota a equação: 83,4 - (0,114 x PVZ), em que PVJ se refere ao peso vivo em jejum. A proteína metabolizável engloba a proteína não degradada no rúmen digestível e a proteína microbiana verdadeira digestível. Logo, para fins de determinação das exigências de proteína para bovinos de corte, é necessário o conhecimento da cinética de degradação protéica dos alimentos no trato gastrintestinal e da medida do crescimento microbiano. As exigências de proteína bruta são obtidas a partir do somatório da proteína degradada no rúmen (PDR) e da proteína não degradada (PNDR). De acordo com o NRC (1996), a PDR pode ser quantificada em $130 \mathrm{~g}$ de $\mathrm{PB} / \mathrm{kg}$ de NDT consumido. Considera ainda que $80 \%$ da proteína microbiana é verdadeira, possuindo digestibilidade de $80 \%$, mesmo valor atribuído à digestibilidade da proteína não degradada no rúmen. A partir dessas considerações, é possível calcular as exigências de proteína bruta para bovinos de corte.

Lana et al. (1992) encontraram exigências líquidas de proteína para animais zebuínos castrados, variando de 162,20 a 102,64 g/kg de PV, para pesos entre 150 e $500 \mathrm{~kg}$. Já Zervoudakis et al. (2002), trabalhando com animais $1 \frac{1}{2}$ holandês-zebu em pastejo, encontraram valores entre 217 e 222 g/kg de PV, para animais com peso vivo variando de 250 a $450 \mathrm{~kg}$.

Objetivou-se, com o presente trabalho, determinar as exigências de proteína de zebuínos castrados, alimentados com diferentes níveis de concentrado na dieta.

\section{Material e Métodos}

O experimento foi realizado no Departamento de Zootecnia da Universidade Federal de Viçosa, em Viçosa-MG. Foram utilizados 19 novilhos anelorados, castrados, com idade e peso vivo médio iniciais de 24 meses e $270 \mathrm{~kg}$, respectivamente. Desses 19 animais, quatro foram abatidos após o período de adaptação de 14 dias, em que todos os animais receberam a mesma dieta, a fim de servirem como referência nos estudos posteriores. O período de adaptação foi curto, uma vez que todos os animais provieram de um mesmo rebanho, submetido a manejo nutricional idêntico. Três animais receberam ração contendo $65 \%$ de volumoso e 35\% de concentrado, na base da matéria seca (MS), em nível de mantença, e compuseram, portanto, o grupo mantença. Os 12 novilhos restantes foram pesados e distribuídos em três tratamentos, com três níveis de concentrado nas dietas (5, 35 e $65 \%$ ), na base da MS total, em delineamento inteiramente casualizado, com quatro repetições. O volumoso foi composto de pré-secado de capim braquiária (Brachiaria brizantha), utilizado por 72 dias, sendo substituído nos 30 dias restantes do experimento pelo pré-secado de capim-tifton 85 (Cynodon sp.). As rações foram balanceadas de forma a serem isoprotéicas. A composição bromatológica das dietas experimentais, quando o volumoso era o pré-secado de braquiária, o que ocorreu durante grande parte do experimento, encontra-se na Tabela 1 .

Os alimentos foram fornecidos à vontade, uma vez ao dia, e ajustados de forma a manter as sobras em torno de 5 a 10\% do fornecido, com água permanentemente à disposição dos animais. A quantidade de ração oferecida foi registrada diariamente e, semanalmente, foram coletadas amostras dos concentrados (por tratamento) e das sobras (por animal). O volumoso foi amostrado diariamente e, no final de

Tabela 1 - Teores médios de matéria seca (MS), matéria orgânica (MO), proteína bruta (PB), extrato etéreo (EE), carboidratos totais (CHOT), fibra em detergente neutro (FDN), carboidratos não-fibrosos (CNF) e nutrientes digestíveis totais (NDT) das dietas experimentais

Table 1 - Average contents of dry matter (DM), organic matter $(O M)$, crude protein $(C P)$, ether extract $(E E)$, total carbohydrates (TCHO), neutral detergent fiber (NDF), non fiber carbohydrates (NFC) and total digestible nutrients (TDN)

\begin{tabular}{|c|c|c|c|}
\hline \multirow[t]{2}{*}{$\begin{array}{l}\text { Itens } \\
\text { Items }\end{array}$} & \multicolumn{3}{|c|}{$\begin{array}{l}\text { Níveis de concentrado na dieta (\%) } \\
\text { Concentrate level in the diet (\%) }\end{array}$} \\
\hline & 5 & 35 & 65 \\
\hline MS (\%) & 32,07 & 49,94 & 67,23 \\
\hline \multicolumn{4}{|l|}{$D M$} \\
\hline $\mathrm{MO}^{1}$ & 91,06 & 92,58 & 93,81 \\
\hline \multicolumn{4}{|l|}{$O M$} \\
\hline $\mathrm{PB}^{1}$ & 15,53 & 14,99 & 14,81 \\
\hline \multicolumn{4}{|l|}{$C P$} \\
\hline $\mathrm{EE}^{1}$ & 1,80 & 2,21 & 2,69 \\
\hline $\mathrm{CHOT}^{1}$ & 73,73 & 75,38 & 76,40 \\
\hline \multicolumn{4}{|l|}{ TCHO } \\
\hline $\mathrm{FDN}^{1}$ & 67,00 & 51,11 & 34,61 \\
\hline \multicolumn{4}{|l|}{$N D F$} \\
\hline $\mathrm{CNF}^{1}$ & 11,70 & 24,27 & 41,79 \\
\hline$N F C$ & & & \\
\hline $\mathrm{NDT}^{2}(\%)$ & 63,83 & 68,41 & 72,41 \\
\hline$T D N$ & & & \\
\hline
\end{tabular}

$1 \%$ na matéria seca ( $\%$ in dry matter).

${ }^{2}$ Costa (2002).

R. Bras. Zootec., v.33, n.3, p.759-769, 2004 
cada período, foi feita uma amostra composta do mesmo. As amostras semanais de concentrado e sobras foram agrupadas, de forma proporcional, em cada período de 28 dias, constituindo-se em amostras compostas, as quais foram pré-secas em estufa ventilada a $65^{\circ} \mathrm{C}$ e processadas em moinho com peneira de malha de $1 \mathrm{~mm}$, para posteriores análises laboratoriais, sendo o mesmo procedimento adotado para as amostras compostas do volumoso.

Os animais foram pesados no início do experimento e, posteriormente, a cada 28 dias, sendo as pesagens sempre precedidas de jejum alimentar de 16 horas. O abate foi efetuado de forma escalonada, com os animais do grupo mantença e os dos tratamentos com 5, 35 e $65 \%$ de concentrado nas dietas abatidos, respectivamente, após 84, 109, 104 e 102 dias de confinamento. Após o abate, o aparelho gastrintestinal de cada animal foi pesado, esvaziado, lavado e seu peso, após escorrer a água de lavagem, foi somado ao dos órgãos e das demais partes do corpo (carcaça, cabeça, couro, cauda, pés e sangue) para determinação do PCVZ (peso de corpo vazio). A relação obtida entre o PCVZ e o peso vivo (PV) dos animais referência foi utilizada para estimativa do PCVZ inicial dos animais que permaneceram no experimento. Dentro de cada tratamento, aleatoriamente, foi sorteado um animal para representá-lo, do qual foram retiradas amostras da cabeça e de um membro anterior e outro posterior, para posteriores separações físicas de músculos, gordura, ossos e couro.

As amostras de sangue foram colhidas imediatamente após o abate, acondicionadas em recipiente de vidro e levadas à estufa de ventilação forçada, a 55$60^{\circ} \mathrm{C}$, durante 48 a 72 horas, para determinação do teor de matéria seca (MS). Em seguida, foram processadas em moinho de bola e acondicionadas em recipientes apropriados, para posteriores análises de nitrogênio total, conforme Silva \& Queiroz (2002), sendo que o teor de proteína foi obtido pelo produto entre o teor de nitrogênio total e o fator 6,25.

A carcaça de cada animal foi dividida em duas metades, as quais foram pesadas e, em seguida, resfriadas em câmara fria a $-5^{\circ} \mathrm{C}$, durante aproximadamente 18 horas. Decorrido esse tempo, a carcaça direita foi retirada da câmara fria e totalmente dissecada, procedendo-se à separação dos componentes músculo, gordura e ossos, que foram, posteriormente, pesados. O músculo e a gordura foram moídos e os ossos, serrados. Foi retirada uma amostra repre- sentativa de cada componente, para determinação direta do teor de proteína da carcaça. Esse procedimento permitiu a obtenção da composição física e química da carcaça pelo método direto.

As amostras de rúmen, retículo, omaso, abomaso, intestino delgado, intestino grosso, gordura interna, mesentério, fígado, coração, rins, pulmões, língua, baço, carne industrial e aparas (esôfago, traquéia e aparelho reprodutor) foram agrupadas de forma proporcional e compuseram a amostra composta de órgãos + vísceras.

À exceção das amostras de sangue, as amostras compostas de órgãos + vísceras, de músculo e de gordura da carcaça (200 g cada amostra), após moídas, e as de couro (100 g), de ossos da carcaça, da cabeça e dos membros (200 g cada), e da cauda (100 g), após seccionadas, foram acondicionadas em vidros com capacidade de $500 \mathrm{~mL}$ e levadas à estufa a $105^{\circ} \mathrm{C}$, por um período de 48 a 96 horas, dependendo da amostra, para determinação da matéria seca gordurosa (MSG).

Posteriormente, as amostras foram submetidas a lavagens sucessivas com éter de petróleo, obtendose a matéria seca pré-desengordurada (MSPD). Em seguida, foram processadas em moinho de bola, para posteriores determinações de nitrogênio total, conforme Silva \& Queiroz (2002). A partir do conhecimento do teor de proteína na MSPD e do peso da amostra submetida ao pré-desengorduramento, determinou-se o respectivo teor na matéria natural.

O conteúdo de proteína da carcaça foi determinado em função da concentração percentual de proteína nas amostras dos constituintes separados (gordura, músculos e ossos) da meia carcaça direita. Já o conteúdo corporal de proteína foi determinado em função da sua concentração percentual nos órgãos e nas vísceras, no couro, no sangue, na cauda, na cabeça, nos pés e nas amostras dos constituintes separados (gordura, músculos e ossos) da meiacarcaça direita. Ou seja, a partir da análise do teor de proteína de todos os tecidos corporais, foi obtida a concentração de proteína corporal, por meio da soma proporcional da quantidade de proteína encontrada em cada tecido.

O conteúdo de proteína retido no corpo dos animais de cada tratamento, e para todos os tratamentos em conjunto foi estimado por meio de equações de regressão do logaritmo do conteúdo corporal de proteína, em função do logaritmo do PCVZ, segundo o ARC (1980), conforme o seguinte modelo: 


$$
\mathrm{Y}=\mathrm{a}+\mathrm{bX}+\mathrm{e}
$$

em que: $\mathrm{Y}=$ logaritmo do conteúdo total de proteína (kg) retido no corpo vazio; $\mathrm{a}=$ constante; $\mathrm{b}=$ coeficiente de regressão do logaritmo do conteúdo de proteína, em função do logaritmo do PCVZ; X = logaritmo do PCVZ; e = erro aleatório.

Para cada tratamento as equações foram construídas adicionando-se os valores relativos aos animais referência, uma vez que para que seja possível o ajuste do modelo de regressão, é necessário que haja considerável dispersão dos dados em torno da média. Se fossem utilizados somente os animais de cada tratamento, sem a inclusão dos animais do grupo referência, os valores do logaritmo do conteúdo total de proteína seriam muito próximos, ou seja, a dispersão dos dados em torno da média seria insuficiente para permitir o ajuste da equação de regressão. Quando os valores referentes aos animais do grupo referência são adicionados, obtém-se dispersão suficiente dos dados em torno da média, uma vez que o conteúdo corporal de proteína dos animais referência foi notadamente diferente de todos os outros animais que permaneceram no experimento.

Derivando-se as equações de predição do conteúdo corporal de proteína, em função do logaritmo do PCVZ, foram obtidas as exigências líquidas de proteína por kg de ganho de PCVZ, a partir de equação do tipo:

$$
\mathrm{Y}^{\prime}=\text { b. } 10^{\mathrm{a}} \cdot \mathrm{X}^{\mathrm{b}-1}
$$

em que: Y' = exigências líquidas de proteína; a e $\mathrm{b}=$ intercepto e coeficiente de regressão, respectivamente, das equações de predição das exigências líquidas de proteína; e X = PCVZ (kg).

Os requisitos de proteína metabolizável para mantença (PMm) e ganho (PMg) e as exigências de proteína bruta foram obtidos segundo o NRC (1996).

Para a conversão do PV em PCVZ, dentro do intervalo de pesos incluído no trabalho, calculou-se a relação entre o PCVZ e o PV dos 12 animais mantidos no experimento.

As exigências para ganho de $1 \mathrm{~kg}$ de PCVZ foram multiplicadas pelo fator 0,90 para se obterem as exigências líquidas para ganho de $1 \mathrm{~kg}$ de PV, conforme relação obtida entre o ganho de peso de corpo vazio e o ganho de peso vivo dos animais do presente trabalho.
As determinações de matéria seca (MS), matéria orgânica (MO), nitrogênio total, extrato etéreo (EE), cinzas e fibra em detergente neutro (FDN) foram realizadas conforme técnicas descritas por Silva \& Queiroz (2002).

Os resultados foram interpretados estatisticamente por meio de análises de variância e regressão, utilizando-se o Sistema de Análises Estatísticas e Genéticas - SAEG (UFV, 1998). As comparações entre as equações de regressão dos parâmetros avaliados para cada tratamento foram realizadas de acordo com a metodologia recomendada por Regazzi (1996) para testar identidade de modelos.

\section{Resultados e Discussão}

A relação obtida para a estimativa do PCVZ a partir do PV dos animais do presente trabalho foi: $\mathrm{PCVZ}=\mathrm{PV}$ x 0,8956, valor próximo àquele recomendado pelo NRC (1996) de 0,891. Silva et al. (2002) e Veloso et al. (2002), trabalhando, respectivamente, com animais Nelore e F1 Limousin x Nelore, inteiros, encontraram valores próximos aos obtidos neste trabalho (0,8968 e 0,8975, respectivamente).

Para conversão das exigências para ganho de PCVZ (GPCVZ) em exigências para ganho de peso vivo (GPV), foi obtida a seguinte relação: GPCVZ = 0,90 x GPV. Desse modo, nas condições deste trabalho, para obter os requisitos líquidos para ganho de $1 \mathrm{~kg}$ de PV, deve-se multiplicar os requisitos para ganho de $1 \mathrm{~kg}$ de PCVZ pelo fator 0,90.

Conforme demonstrado por Robelin \& Geay (1984), o PCVZ é influenciado pelo nível de concentrado (NC) da dieta em função de diferenças observadas no enchimento do trato gastrintestinal. De maneira geral, animais submetidos a dietas com maiores proporções de alimento volumoso tendem a apresentar maior conteúdo do trato gastrintestinal e, conseqüentemente, menor valor para o PCVZ quando comparado ao peso vivo. Para animais alimentados com mais concentrado na dieta verifica-se o contrário, ou seja, menor conteúdo do trato gastrintestinal e maior valor para o PCVZ. Em função dessa variação, foi efetuada a regressão do PCVZ em função do PV final, ou o peso de abate dos animais, e do NC nas dietas. A equação obtida foi: $\mathrm{PCVZ}=8,1343+0,8510$ * PV + 0,2232 NC $\left(r^{2}=0,96\right)$.

Os parâmetros das equações de regressão do logaritmo do conteúdo de proteína $(\mathrm{kg})$ no corpo vazio, em função do logaritmo do PCVZ são apresen- 
tados na Tabela 2. O teste de identidade entre os modelos, aplicado às equações de regressão do logaritmo do conteúdo corporal de proteína, em função do logaritmo do PCVZ, para os três níveis de concentrado na dieta, indicou não haver diferença entre os tratamentos. Portanto, pode-se recomendar o uso da equação conjunta, que é comum aos três níveis de inclusão de concentrado nas rações.

De acordo com a equação relativa ao resultado para os tratamentos em conjunto, observou-se aumento no conteúdo corporal de proteína (de 48,25 para 63,93 kg), com o aumento do PV dos animais de 250 para $400 \mathrm{~kg}$. Já a concentração de proteína, em $\mathrm{g} / \mathrm{kg}$ de PCVZ, diminuiu com o aumento do PV (Tabela 3).

Lana et al. (1992), trabalhando com bovinos zebuínos castrados encontrou resultados semelhantes. O conteúdo corporal de proteína (g/kg de PCVZ) diminuiu de 220 para 190, quando o peso vivo dos animais aumentou de 250 para $400 \mathrm{~kg}$. Boin (1995), utilizando animais Nelore castrados, verificou reduções do conteúdo de proteína (g/kg de PCVZ) de 125 para 115, quando o corpo vazio aumentou de 300 para $400 \mathrm{~kg}$. Tendências semelhantes foram encontradas por vários autores, mesmo trabalhando com animais inteiros (Ferreira et al., 1999; Véras et al., 2000; Silva et al., 2002; Veloso et al., 2002). Observa-se que o conteúdo corporal de proteína sofre redução mais significativa em animais castrados, uma vez que depositam gordura mais pronunciadamente. Esse comportamento da composição corporal explica os menores requerimentos de proteína de bovinos castrados em relação aos inteiros.

As exigências líquidas de proteína, por kg de ganho de PCVZ, são apresentadas na Tabela 4. Conforme citado anteriormente, para conversão das exigências de ganho de PCVZ em exigências para ganho de peso vivo, deve-se multiplicar as primeiras pelo fator 0,90 .

Como esperado, observou-se que as exigências de proteína para ganho de PCVZ decresceram à medida que o PV dos animais elevou, obviamente em virtude do aumento da concentração de gordura no ganho, em detrimento ao de proteína. Isso decorreu do fato de o tecido adiposo ter se desenvolvido mais intensamente, com concomitante desaceleração do crescimento muscular, à medida que aumentou o peso dos animais que, provavelmente, já tinham atingido a idade à maturidade. As exigências líquidas de
Tabela 2 - Parâmetros das equações de regressão do logaritmo dos conteúdos de proteína $(\mathrm{kg})$ no corpo vazio, em função do logaritmo do peso do corpo vazio $(\mathrm{kg})$ de bovinos anelorados, e os respectivos coeficientes de determinação $\left(\mathrm{r}^{2}\right)$, para os diferentes níveis de concentrado (NC) na ração e em conjunto

Table 2 - Parameters of logarithm regression equations of protein $(\mathrm{kg})$ in empty body, in function of empty body weight $(\mathrm{kg})$ of Nelore steers, and respective coefficients of determination $\left(r^{2}\right)$, for different concentrate levels $(C L)$ in the diet, and in overall

\begin{tabular}{cccc}
\hline & \multicolumn{3}{c}{ Parâmetros } \\
NC (\%) & $\begin{array}{c}\text { Intercepto (a) } \\
\text { Intercept }\end{array}$ & $\begin{array}{c}\text { Coeficiente (b) } \\
\text { Slope }\end{array}$ & $\mathrm{r}^{2}$ \\
\hline \multicolumn{3}{c}{$\begin{array}{c}\text { Proteína }(\mathrm{kg}) \\
\text { Protein }(\mathrm{kg})\end{array}$} \\
\hline 5 & \multicolumn{3}{c}{0,6467} \\
35 & 0,1666 & 0,5909 & 0,94 \\
65 & 0,2922 & 0,74 \\
Conjunto & 0,2825 & 0,5952 & 0,91 \\
Overall & 0,2765 & 0,5987 & 0,85 \\
\hline
\end{tabular}

Tabela 3 - Estimativa do conteúdo de proteína no peso de corpo vazio ( $\mathrm{g} / \mathrm{kg}$ PCVZ) de bovinos anelorados, em função do peso vivo (PV)

Table 3 - Estimated content of protein in the empty body weight $(\mathrm{g} / \mathrm{kg} E B W)$ of anelorados steers, as a function of live weight ( $L W)$

\begin{tabular}{cc}
\hline PV $(\mathrm{kg})$ & $\begin{array}{c}\text { Proteína }(\mathrm{g} / \mathrm{kg} \text { PCVZ) } \\
\text { Protein }(\mathrm{g} / \mathrm{kg} \mathrm{EBW})\end{array}$ \\
\hline $25(\mathrm{~kg})$ & 215,49 \\
300 & 200,28 \\
350 & 188,27 \\
400 & 178,45 \\
\hline
\end{tabular}

$\mathrm{PCVZ}=\mathrm{PV} * 0,8956(E B W=L W * .8956)$.

Tabela 4 - Exigências líquidas de proteína, em g por kg de ganho de peso de corpo vazio (g/kg GPCVZ) de bovinos anelorados, em função do peso vivo (PV)

Table 4 - Net requirements of protein, in $\mathrm{g} / \mathrm{kg}$ of empty body gain $(\mathrm{g} / \mathrm{kg} E B G$, of anelorados steers, as a function of live weight $(L W)$

\begin{tabular}{cc}
\hline PV $(\mathrm{kg})$ & $\begin{array}{c}\text { Exigência de proteína }(\mathrm{g} / \mathrm{kg} \mathrm{GPCVZ}) \\
\text { Protein requirement }(\mathrm{g} / \mathrm{kg} \mathrm{EBG})\end{array}$ \\
\hline 250 & 129,01 \\
300 & 119,91 \\
350 & 112,72 \\
400 & 106,84 \\
\hline
\end{tabular}

$\mathrm{PCVZ}=\mathrm{PV}{ }^{*} 0,8956(E B W=L W * .8956)$. 
proteína encontradas para um animal de $400 \mathrm{~kg}$, 106,84 g de proteína por kg de GPCVZ foram $13 \%$ inferiores àquelas determinadas para um bovino com o mesmo peso vivo por Lana et al. (1992). Gonçalves et al. (1991a) encontraram exigências líquidas de proteína, para animais Nelore castrados, superiores às deste estudo, variando de 173,74 a 132,80 g de proteína por cada kg de ganho de peso de corpo vazio, para animais com 250 e 400 kg de PCVZ, respectivamente.

Com os dados obtidos no trabalho de Paulino et al. (2003), foi obtida a seguinte equação para estimativa da proteína retida (PR), em g/dia, em função do ganho de peso vivo em jejum (GPVJ), em kg/dia, e da energia retida (ER), em Mcal/dia:

$\mathrm{PR}=-37,0401+213,024 \mathrm{GPVJ}-17,1430 \mathrm{ER} ;$ $\left(r^{2}=0,48\right)$.

O NRC (1996) preconiza a equação PR = GPVJ $\{268$ - [29,4 (ER/GPVJ] $\}$ para estimativa dos requerimentos líquidos de proteína para ganho (PR). Ao se utilizar a equação obtida neste experimento, considerando um bovino de $400 \mathrm{~kg}$ ganhando $1 \mathrm{~kg}$ de peso vivo por dia e substituindo o valor de ER para este animal, de acordo com a equação obtida por Paulino et al. (2003), de 5,34 Mcal/dia, obteve-se retenção líquida diária de proteína de 84,44 g. Substituindo-se estes dados na equação do NRC (1996), obtém-se retenção líquida diária de proteína de 111,00 g, valor $24 \%$ superior ao encontrado neste estudo.

Na Tabela 5, são apresentadas as exigências de proteína metabolizável (PM), calculadas conforme metodologia proposta pelo NRC (1996), utilizando-se valores referentes às exigências líquidas de proteína para ganho de peso, relativos aos dados em conjunto.

Pode-se observar que as exigências de proteína metabolizável para mantença (PMm) aumentaram com a elevação do PV, uma vez que os requisitos de proteína para mantença são função do PV dos animais, como estabelece o NRC (1996). Para os requisitos de PM para ganho (PMg), adotaram-se as recomendações do NRC (1996), ou seja, para animais com PVJ acima de $300 \mathrm{~kg}$ foi utilizada eficiência de utilização constante de 49,2\%. Para os animais com peso vivo em jejum inferior a $300 \mathrm{~kg}$, utilizou-se a seguinte equação para o cálculo da eficiência da PM para ganho: Eficiência = [83,4 $(0,114$ x PVJ)]. Esta equação foi proposta por Ainslie et al. (1993) e adotada pelo NRC (1996). Para um animal de $400 \mathrm{~kg}$ de PV, ganhando $1 \mathrm{~kg}$ de PV por dia, a exigência de PM total, de acordo com os dados deste experimento, foi de $557 \mathrm{~g}$, portanto, $9 \%$ inferior ao recomendado pelo NRC (1996) para um taurino castrado, com o mesmo peso e apresentando a mesma taxa de ganho de peso.

A partir das exigências de proteína metabolizável apresentadas na Tabela 5, e utilizando-se o protocolo recomendado pelo NRC (1996) para conversão dos requisitos totais de PM em exigências de proteína bruta (PB), foram calculados os requisitos diários totais de $\mathrm{PB}$ e as exigências de proteína degradada e não-degradada no rúmen (Tabela 6), utilizando-se o consumo médio de nutrientes digestíveis totais (NDT) de $17,84 \mathrm{~g} / \mathrm{kg}$ de PCVZ, obtido por Paulino et al. (2003). A PMg, por kg de PCVZ, foi corrigida para ganho de PV, multiplicando-a pelo fator 0,90.

À medida que o peso vivo do animal aumentou, menor foi sua exigência em proteína não-degradável no rúmen (Tabela 6), possibilitando maior participação da proteína degradável no rúmen para o suprimento das exigências totais de PB. Dessa forma, animais mais pesados em fase de terminação podem receber maiores níveis de nitrogênio não-protéico em suas dietas, sem afetar o desempenho (Silva et al., 2002). Resultado semelhante foi obtido por Lana et al. (1992), trabalhando com animais Nelore e cruzados Europeu x Zebu, castrados, em que animais com peso vivo de $300 \mathrm{~kg}$ já não apresentaram exigências de proteína não degradável, quando toda a proteína bruta foi suprida somente pela proteína degradável no rúmen. Para um animal de $400 \mathrm{~kg}$ de PV, as exigências

Tabela 5 - Exigências de proteína metabolizável para mantença $(\mathrm{PMm})$ e para ganho de peso $(\mathrm{PMg})$ de $1 \mathrm{~kg}$ de $\mathrm{PV}$ de bovinos anelorados, em função do peso vivo (PV)

Table 5 - Metabolizable protein requirements for maintenance $(\mathrm{MPm})$ and gain $(\mathrm{MPg})$ of $1 \mathrm{~kg} \mathrm{LW}$ of Nelore steers, as a function of live weight $(L W)$

\begin{tabular}{ccc}
\hline $\mathrm{PV}(\mathrm{kg})$ & $\mathrm{PMm}^{1}(\mathrm{~g} / \mathrm{kg} \mathrm{GPV})$ & $\mathrm{PMg}^{2}(\mathrm{~g} / \mathrm{kg} \mathrm{GPV})$ \\
$L W(\mathrm{~kg})$ & $\mathrm{MPm}^{1}(\mathrm{~g} / \mathrm{kg} \mathrm{LWG})$ & $\mathrm{MPg}^{2}(\mathrm{~g} / \mathrm{kg} \mathrm{LWG})$ \\
\hline 250 & 238,91 & 22,91 \\
300 & 273,92 & 227,23 \\
350 & 307,49 & 229,10 \\
400 & 339,88 & 217,14 \\
\hline
\end{tabular}

$\mathrm{PCVZ}=\mathrm{PV}{ }^{*} 0,8956(E B W=L W * .8956)$.

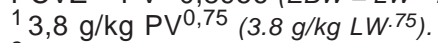

2 Exigência líquida/0,492 para $P V J>300 \mathrm{~kg}$.

Exigência líquida/(83,4 - $(0,114 \times \mathrm{PVJ}))$ para $\mathrm{PVJ}=300 \mathrm{~kg}$.

2 Net requirement/.492 for EQEBW $>300 \mathrm{~kg}$.

Net requirement/(83.4 - (0.114 x EQEBW $))$, for EQEBW $=300 \mathrm{~kg}$.

R. Bras. Zootec., v.33, n.3, p.759-769, 2004 
totais de PB encontradas neste trabalho (835,31 g/dia) estão próximas daquelas $(881,16$ g/dia) registradas por Lana et al. (1992).

As exigências líquidas e totais de proteína e energia, obtidas no trabalho de Paulino et al. (2003), para diferentes pesos vivos e taxas de ganho de peso vivo são apresentadas na Tabela 7. As exigências totais de EM (mantença $+1 \mathrm{~kg}$ de PV) e de NDT de um animal pesando $400 \mathrm{~kg}$, alimentado com uma dieta com teor de EM de 2,3 Mcal/kg de MS, foram, respectivamente, de 27,44 Mcal/dia e 7,59 kg/dia. Gonçalves et al. (1991b) obtiveram exigência líquida de energia para mantença e ganho de $1 \mathrm{~kg}$ de PV de bovinos Nelore castrados, de 12,35 Mcal/dia, valor bastante próximo às 11,48 Mcal de energia líquida requeridas para os animais do presente trabalho (Paulino et al., 2003). Entretanto, quando se compara a exigência líquida de energia para ganho de $1 \mathrm{~kg}$ de peso vivo, observa-se que o valor encontrado por Gonçalves et al. (1991b), de 7,00 Mcal/kg de PV, é aproximadamente $24 \%$ superior ao encontrado neste estudo. As exigências totais são próximas, porque a exigência líquida para mantença encontrada pelo primeiro autor foi de 5,35 Mcal/dia, portanto $13 \%$ inferior à obtida neste trabalho. A exigência total de proteína metabolizável (mantença + ganho de 1 kg de PV) encontrada por Gonçalves et al. (1991a) para o mesmo animal descrito acima foi de 492,90 g/dia, $4 \%$ inferior à exigência de 512,07 g de $\mathrm{PM}$ /dia, determinada para os animais deste trabalho.

Lana et al. (1992) encontrou exigência diária total de energia metabolizável para bovinos Nelore de 400 kg, castrados, ganhando $1 \mathrm{~kg}$ de peso vivo por dia e alimentados com dieta contendo 2,2 Mcal de EM/kg de MS, de 25,24 Mca/dia; valor 8\% inferior aquele apresentado na Tabela 7 (27,44 Mcal/d) para animais anelorados castrados, com mesmo peso vivo e mesma taxa de ganho.

Percebe-se, pela Tabela 7, que à medida que o peso corporal se eleva, ou seja, aumenta de 250 para $400 \mathrm{~kg}$ de PV, as exigências totais tanto de energia (EM ou NDT) quanto de proteína bruta também aumentam. Entretanto, esse comportamento somente é possível devido ao fato de as exigências de mantença estarem incluídas no cálculo das exigências totais. Como as exigências de mantença (energia e proteína) são calculadas diretamente em função do peso vivo, quando o peso do animal aumenta, suas exigências de mantença também aumentam, embora em termos absolutos. Já o comportamento das exigências para ganho é distinto. À medida que o peso corporal se eleva, quando o acréscimo de gordura corporal passa a ser mais pronunciado, as exigências líquidas de energia também aumentam, conforme demonstrado na Tabela 7. Por outro lado, as exigências de proteína para ganho diminuem, já que animais mais pesados apresentam retenção de proteína corporal reduzida. Portanto, nota-se a importância de se conhecer o comportamento das exigências nutricionais dos animais de maneira conjunta, uma vez que energia e proteína estão intimamente associadas no metabolismo dos bovinos.

\begin{tabular}{|c|c|c|c|c|}
\hline \multirow{3}{*}{$\begin{array}{l}\text { Table } 6 \text { - } \\
\begin{array}{c}\text { PV }(\mathrm{kg}) \\
L W(\mathrm{~kg})\end{array}\end{array}$} & \multicolumn{4}{|c|}{$\begin{array}{l}\text { Requirements of rumen degradable protein (RDP), rumen undegradable } \\
\text { protein }(R U D P) \text { and crude protein }(C P) \text {, in } \mathrm{g} / \mathrm{d} \text {, of Nelore steers, as a function } \\
\text { of live weight }(L W) \text {, for maintenance and gain of } 1 \mathrm{~kg} \text { of } L W \text {, and mean values } \\
\text { for TDN intake }(\mathrm{kg} / \mathrm{d})\end{array}$} \\
\hline & PDR (g/dia) & PNDR (g/dia) & PB (g/dia) & NDT (kg/dia) \\
\hline & $R D P(g / d)$ & $R U D P(g / d)$ & $C P(g / d)$ & $T D N(\mathrm{~kg} / \mathrm{d})$ \\
\hline 250 & 519,28 & 133,99 & 653,28 & 4,00 \\
\hline 300 & 623,14 & 99,52 & 722,66 & 4,80 \\
\hline 350 & 727,00 & 60,50 & 787,50 & 5,60 \\
\hline 400 & 830,86 & 4,46 & 835,31 & 6,40 \\
\hline
\end{tabular}

$\mathrm{PCVZ}=\mathrm{PV} * 0,8956(E B W=L W * .8956)$. 
Tabela 7 - Exigências nutricionais de energia e proteína para animais anelorados castrados, em função do peso vivo (PV) e do ganho médio diário (GMD)

Table 7 - Nutritional requirements of energy and protein for Nelore steers, as a function of live weight ( $L W)$, according to different levels of average daily gain (ADG)

\begin{tabular}{|c|c|c|c|c|c|}
\hline $\begin{array}{l}\text { Peso vivo }(\mathrm{kg}) \\
\text { Live weight }(\mathrm{kg})\end{array}$ & & 250 & 300 & 350 & 400 \\
\hline & & \multicolumn{4}{|c|}{$\begin{array}{l}\text { Exigências de mantença } \\
\text { Maintenance requirements }\end{array}$} \\
\hline $\begin{array}{l}\mathrm{ELm}^{1} \\
\mathrm{NEm}\end{array}$ & $\mathrm{Mcal} / \mathrm{d}$ & 4,31 & 4,94 & 5,55 & 6,14 \\
\hline \multirow{2}{*}{$\begin{array}{l}\mathrm{PMm}^{2} \\
\mathrm{MPm}\end{array}$} & $\mathrm{g} / \mathrm{d}$ & 238,91 & 273,92 & 307,49 & 339,88 \\
\hline & & \multicolumn{4}{|c|}{$\begin{array}{c}\text { Exigências de ganho } \\
\text { Gain requirements } \\
\text { ELg para ganho, Mcal/d } 3 \\
\text { NE for gain }(\mathrm{Mcal} / \mathrm{d})\end{array}$} \\
\hline \multirow{2}{*}{$\begin{array}{l}\text { GMD } \\
A D G\end{array}$} & $0,50 \mathrm{~kg} / \mathrm{d}$ & 1,92 & 2,20 & 2,47 & 2,73 \\
\hline & $1,00 \mathrm{~kg} / \mathrm{d}$ & \multicolumn{4}{|c|}{$\begin{array}{c}\text { PM para ganho }(\mathrm{g} / \mathrm{d})^{4,5} \\
M P \text { for gain }(\mathrm{g} / \mathrm{d})\end{array}$} \\
\hline \multirow{2}{*}{$\begin{array}{l}\text { GMD } \\
A D G\end{array}$} & $0,50 \mathrm{~kg} / \mathrm{d}$ & 63,28 & 60,29 & 55,28 & 46,23 \\
\hline & $1,00 \mathrm{~kg} / \mathrm{d}$ & \multicolumn{4}{|c|}{$\begin{array}{l}\text { Exigências totais } \\
\text { Total requirements } \\
\text { EM (Mcal/d) }{ }^{6} \\
M E(M c a l / d)\end{array}$} \\
\hline \multirow{2}{*}{$\begin{array}{l}\text { GMD } \\
A D G\end{array}$} & $0,50 \mathrm{~kg} / \mathrm{d}$ & 13,06 & 14,98 & 16,81 & 18,59 \\
\hline & $1,00 \mathrm{~kg} / \mathrm{d}$ & \multicolumn{4}{|c|}{$\begin{array}{c}\operatorname{NDT}(\mathrm{kg} / \mathrm{d})^{7} \\
\operatorname{TDN}(\mathrm{kg} / \mathrm{d})\end{array}$} \\
\hline \multirow{2}{*}{$\begin{array}{l}\text { GMD } \\
A D G\end{array}$} & $0,50 \mathrm{~kg} / \mathrm{d}$ & 3,61 & 4,14 & 4,65 & 5,14 \\
\hline & $1,00 \mathrm{~kg} / \mathrm{d}$ & \multicolumn{4}{|c|}{$\begin{array}{c}\text { PB }(g / d)^{8} \\
C P(g / d)\end{array}$} \\
\hline \multirow{2}{*}{$\begin{array}{l}\text { GMD } \\
A D G\end{array}$} & $0,50 \mathrm{~kg} / \mathrm{d}$ & 450 & 497 & 540 & 575 \\
\hline & $1,00 \mathrm{~kg} / \mathrm{d}$ & 643 & 696 & 740 & 762 \\
\hline
\end{tabular}

$1 \mathrm{ELm}=74,51 \mathrm{kcal} / \mathrm{PCVZ} Z^{0,75}\left(\mathrm{NEm}=74.51 \mathrm{kcal} / \mathrm{EBW} \cdot{ }^{75}\right)$ (Paulino et al., 2003).

$2 \mathrm{PMm}=3,8 \mathrm{~g} / \mathrm{kg} \mathrm{PV} 0,75$ (MPm $=3.8 \mathrm{~g} / \mathrm{kg} L W^{.75}$ ) (NRC, 1996).

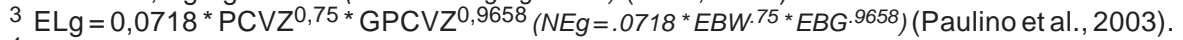

${ }^{4} \mathrm{PR}=-37,0401-(17,1430 * \mathrm{ELg})+(213,024 * \mathrm{GMD})$ (Paulino et al., 2003).

$R P=-37.0401-(17.1430 * N E g)+(213.024 * A D G)($ Paulino et al., 2003).

$5 \mathrm{PM}=$ exigências líquidas/0,492 para $\mathrm{PVJ}>300 \mathrm{~kg}$ ou exigências líquidas/[83,4-(0,114 * $\mathrm{PVJ})]$ para $\mathrm{PVJ}=300 \mathrm{~kg}(\mathrm{NRC}, 1996)$

$\mathrm{MP}=$ Net requirement $/ .492$ for $E Q E B W>300 \mathrm{~kg}$.

$2 \mathrm{Net}$ requirement/(83.4 - (.114 x EQEBW)), for EQEBW = $300 \mathrm{~kg}(\mathrm{NRC}, 1996)$.

${ }^{6} \mathrm{k}_{\mathrm{m}}=0,66$ e $\mathrm{k}_{\mathrm{f}}=0,26$ (dieta com 2,3 Mcal $/ \mathrm{kg}$ de MS) (diet with $2.3 \mathrm{Mcal} / \mathrm{kg} D M$ ).

$7 \mathrm{NDT}=\mathrm{EM} / 0,82 / 4,409(T D N=M E / .82 / 4.409)(N R C, 1996)$.

$8 \mathrm{~PB}=\mathrm{PM}$ total $/ 0,672(C P=$ total MP/.672) (NRC, 1996).

As exigências líquidas para ganho de PCVZ foram convertidas para ganho de PV através da multiplicação pelo fator 0,90 , encontrado neste trabalho.

The net requirement for EBWG were converted to $L W G$ requirements by the factor .90 .

$P C V Z=P V * 0,8956(E B W=L W * .8956)$. 


\section{Conclusões}

Os níveis de concentrado na dieta não afetaram as exigências líquidas de proteína para ganho de peso.

O requerimento líquido de proteína para ganho de peso de animais anelorados castrados, em g/dia, pode ser obtido a partir da equação: $\mathrm{PR}=-37,0401+213,024 \mathrm{GPVJ}-17,1430 \mathrm{ER}$.

\section{Literatura Citada}

AGRICULTURAL RESEARCH COUNCIL - ARC. The nutrient requirements of ruminants livestock. London: 1980. 351p.

AINSLIE, S.J.; FOX, D.G.; PERRY, T.C. et al. Predicting amino acid adequacy of diets fed to Holstein steers. Journal of Animal Science, v.71, p.1312-1319, 1993.

ALMEIDA, M.I.V.; FONTES, C.A.A.; ALMEIDA, F.Q. et al. Conteúdo corporal e exigências líquidas de energia e proteína de novilhos mestiços Holandês-Gir em ganho compensatório. Revista Brasileira de Zootecnia, v.30, n.1, p.205-214, 2001.

ANUALPEC. Anuário da pecuária brasileira. São Paulo: FNP Consultoria \& Comércio, 2002. 400p.

ARAÚJO, G.G.L.; SILVA, J.F.C.; VALADARES FILHO, S.C. et al. Composição corporal e exigências líquidas de energia e proteína de bezerros alimentados com dietas contendo diferentres níveis de volumoso. Revista Brasileira de Zootecnia, v.27, n.5, p.1013-1022, 1998.

BACKES, A.A.; SANCHEZ, L.M.B.; GONÇALVES, M.B.F. et al. Composição corporal e exigências líquidas de energia e proteína para ganho de peso de novilhos Santa Gertrudis. Revista Brasileira de Zootecnia, v.31, n.3, p.2307-2313, 2002.

BOIN, C. Alguns dados sobre exigências de energia e de proteína de zebuínos. In: SIMPÓSIO INTERNACIONAL SOBRE EXIGÊNCIAS NUTRICIONAIS DE RUMINANTES, 1., 1995, Viçosa, MG. Anais... Viçosa, MG: Universidade Federal de Viçosa, 1995. p.457-466.

BULLE, M.L.M.; RIBEIRO, F.G.; LEME, P.R. et al. Exigências líquidas de energia e proteína de tourinhos de dois grupos genéticos alimentados com dietas de alto teor de concentrado. Revista Brasileira de Zootecnia, v.31, n.1S, p.436-443, 2002.

CARVALHO, D.R. Composição corporal e exigências nutricionais de macroelementos inorgânicos de bovinos. Viçosa, MG: Universidade Federal de Viçosa, 1989. 84p. Dissertação (Mestrado em Zootecnia) - Universidade Federal de Viçosa, 1989.

CARVALHO, P.A.; SANCHEZ, L.M.B.; PIRES, C.C. et al. Composição corporal e exigências líquidas de proteína e energia para ganho de peso de bezerros machos de origem leiteira do nascimento aos 110 dias de idade. Revista Brasileira de Zootecnia, v.32, n.6, p.1484-1491, 2003.

COSTA, M.A. Desempenho de novilhos zebuínos e validação das equações do NRC (2001) para predizer o valor energético dos alimentos nas condições brasileiras. Viçosa, MG: Universidade Federal de Viçosa, 2002. 81p. Dissertação (Mestrado em Zootecnia) - Universidade Federal de Viçosa, 2002.

R. Bras. Zootec., v.33, n.3, p.759-769, 2004
ESTRADA, L.H.C.; FONTES, C.A.A.; JORGE, A.M. et al. Exigências nutricionais de bovinos não-castrados em confinamento. 1. Conteúdo corporal e exigências liquidas de proteína e energia para ganho de peso. Revista Brasileira de Zootecnia, v.26, n.3, p.575-583, 1997.

FERREIRA, M.A.; VALADARES FILHO, S.C.; COELHO DA SILVA, J.F. et al. Composição corporal e exigências líquidas de proteína e energia para ganho de peso de bovinos F1 Simental x Nelore. Revista Brasileira de Zootecnia, v.28, n.2, p.352-360, 1999.

FONTES, C.A.A. Composição corporal, exigências líquidas de nutrientes para ganho de peso e desempenho produtivo de animais zebuínos e mestiços europeu-zebu. Resultados experimentais. In: SIMPÓSIO INTERNACIONAL SOBRE EXIGÊNCIAS NUTRICIONAIS DE RUMINANTES, 1., 1995, Viçosa. Anais... Viçosa: Universidade Federal de Viçosa, 1995. p.419-455.

FREITAS, J.A. Composição corporal e exigência de energia e proteína de bovinos (zebuínos e mestiços) e bubalinos não castrados, em confinamento. Viçosa, MG: UniversidadeFederal de Viçosa, 1995. 132p. Dissertação (Mestrado em Zootecnia) - Universidade Federal de Viçosa, 1995.

GEAY, Y. Energy and protein utilization in growing cattle. Journal of Animal Science, v.58, n.3, p.766-778, 1984.

GONÇALVES, L.C.; SILVA, J.F.C.; CASTRO, A.C.G. et al. Exigências de proteína para novilhos de cinco grupos genéticos. Revista Brasileira de Zootecnia, v.20, n.5, p.430-438, 1991a.

GONÇALVES, L.C.; SILVA, J.F.C.; VALADARES FILHO, S.C. et al. Exigências de energia para cinco grupos genéticos de novilhos. Revista Brasileira de Zootecnia, v.20, n.5, p.421-429, 1991b.

LANA, R.P.; FONTES, C.A.A.; PERON, A.J. et al. Composição corporal e do ganho de peso e exigências de energia, proteína e macroelementos minerais (Ca, P, Mg, Na e K), de novilhos de cinco grupos raciais. 2. exigências de energia e proteína. Revista Brasileira de Zootecnia, v.21, n.3, p.528-537, 1992.

MARGON, A.L. Requerimentos de macrominerais (Ca, P, Mg, Na e K) para engorda de novilhos zebu. Viçosa, MG: Universidade Federal de Viçosa, 1981. 74p. Dissertação (Mestrado em Zootecnia) - Universidade Federal de Viçosa, 1981.

NATIONAL RESEARCH COUNCIL - NRC. Nutrient requirements of beef cattle. 7.ed. Washington, D.C.: 1996. 242p.

PAUlinO, M.F.; FONTES, C.A.A.; JORGE, A.M. et al. Composição corporal e exigências de energia e proteína para ganho de peso de bovinos de quatro raças zebuínas. Revista Brasileira de Zootecnia, v.28, n.3, p.627-633, 1999.

PAULINO, P.V.R.; VALADARES FILHO, S.C.; PAULINO, M.F. et al. Eficiência de uso da energia metabolizável para mantença e ganho de peso e exigências energéticas de novilhos anelorados. In: REUNIÃO ANUAL DA SOCIEDADE BRASILEIRA DE ZOOTECNIA, 40, 2003, Santa Maria. Anais... Santa Maria: Infovia, 2003. CD-ROM. Nutrição de Ruminantes.

PIRES, K.C. Exigências nutricionais de bovinos de corte em acabamento. I - composição corporal e exigências de proteína para ganho de peso. Revista Brasileira de Zootecnia, v.22, n.1, p.110, 1993.

REGAZZI, J.A. Teste para verificar a identidade de modelos de regressão. Pesquisa Agropecuária Brasileira, v.31, n.1, p.117, 1996.

ROBELIN, J.; GEAY, Y. Body composition of cattle as affected by physiological status, breed, sex and diet. In: GILCHRIST, F.M.C.; MACKIE, R.I. (Eds). Herbage nutrition in the 
subtropics and tropics. Johannesburg: Science Press, 1984. p.525-547.

ROCHA, E.O.; FONTES, C.A.A. Composição corporal, composição do ganho de peso e exigências nutricionais de novilhos de origem leiteira. Revista Brasileira de Zootecnia, v.28, n.1, p.159-168, 1999.

SALVADOR, M. Exigências de energia e proteína para engorda de novilhos azebuados. Viçosa: Universidade Federal de Viçosa, 1990. 70p. Dissertação (Mestrado em Zootecnia)-Universidade Federal de Viçosa, 1980.

SIGNORETTI, R.D.; SILVA, J.F.C.; VALADARES FILHO, S.C. et al. Composição corporal e exigências líquidas de energia e proteína de bezerros da raça Holandesa alimentados com dietas contendo diferentes níveis de volumoso. Revista Brasileira de Zootecnia, v.28, n.1, p.195-204, 1999.

SILVA, D.J.; QUEIROZ, A.C. Análise de alimentos (métodos químicos e biológicos). 3.ed. Viçosa, MG: Universidade Federal de Viçosa, 2002. 235p.

SILVA, F.F.; VALADARES FILHO, S.C.; ÍTAVO, L.C.V. et al. Composição corporal e requisitos energéticos e protéicos de bovinos Nelore, não-castrados, alimentados com rações contendo diferentes níveis de concentrado e proteína. Revista Brasileira de Zootecnia, v.31, n.1S, p.503-513, 2002.

SILVA SOBRINHO, A.G. Requerimentos de macrominerais (Ca, P, Mg, Na e K) para seis grupos genéticos de bovídeos. Viçosa, MG:UniversidadeFederal de Viçosa, 1984.61p.Dissertação (Mestrado em Zootecnia) - Universidade Federal de Viçosa, 1984.

SOARES, J.E. Composição corporal e exigências de macroelementos minerais (Ca, $\mathrm{P}, \mathrm{Mg}, \mathrm{K}$ e $\mathrm{Na}$ ) para ganho de peso em bovinos (zebuínos e mestiços) e bubalinos. Viçosa, MG: Universidade Federal de Viçosa, 1994. 77p. Dissertação (Mestrado em Zootecnia) - Universidade Federal de Viçosa, 1994.
TEIXEIRA, J.C. Exigências de energia e proteína, composição e área corporal e principais cortes da carcaça em seis grupos genéticos de bovídeos. Viçosa, MG: Universidade Federal de Viçosa, 1984. 94p. Tese (Doutorado em Zootecnia) Universidade Federal de Viçosa, 1984.

UNIVERSIDADE FEDERAL DE VIÇOSA - UFV. SAEG Sistema de Análises Estatísticas e Genéticas. Viçosa, MG: Universidade Federal de Viçosa, 1998.

VELOSO, C.M.; VALADARES FILHO, S.C.; GESUALDI JR., A. et al. Composição corporal e exigências energéticas e protéicas de bovinos F1 Limousin x Nelore, não-castrados, alimentados com rações contendo diferentes níveis de concentrado. Revista Brasileira de Zootecnia, v.31, n.3, p.1273-1285, 2002.

VÉRAS, A.S.C.; VALADARES FILHO, S.C.; SILVA, J.F.C. et al. Composição corporal e requisitos energéticos e protéicos de bovinos Nelore, não-castrados, alimentados com rações contendo diferentes níveis de concentrado. Revista Brasileira de Zootecnia, v.29, n.8, p.2379-2389, 2000.

WILKERSON, V.A.; KLOPFENSTEIN, T.J.; BRITTON, R.A. et al. Metabolizable protein and amino acid requirements of growing beef cattle. Journal of Animal Science, v.71, p.2777-2784, 1993.

ZERVOUDAKIS, J.T.; PAULINO, M.F.; DETMANN, E. et al. Conteúdo corporal e exigências líquidas de proteína e energia de novilhos suplementados no período das águas. Revista Brasileira de Zootecnia, v.31, n.1S, p.530-537, 2002.

Recebido em: 20/11/02 Aceito em: 08/09/03 